\title{
CARTA DEL DIRECTOR
}

Estimados lectores de la revista Biomecánica:

Como nuevo Director de la revista, me gustaría, en primer lugar, destacar a Daniel Rodríguez y su equipo por su trayectoria de tantos años ayudando a que la Biomecánica Deportiva, la Biomedicina y los Biomateriales tengan un foro de debate científico propio en este país a través de los Congresos que se celebran anualmente y especialmente a través de la revista Biomécanica. En segundo lugar, me gustaría agradecer a la Sociedad Ibérica de Biomecánica y Biomateriales (SIBB) la confianza que deposita en mí y en mi equipo.

Como bien sabéis, la SIBB tiene como objetivo de agrupar a cirujanos, médicos, ingenieros, físicos, químicos y especialistas en educación física; en un foro para el intercambio de ideas y al mismo tiempo como estímulo para la investigación.

Un elemento fundamental para lograr dicho objetivo es la revista "Biomecánica", originalmente publicada en papel y actualmente en formato digital "open access", sin cargos para el autor del artículo o el lector del mismo. En la revista se publican revisiones de un tema específico, trabajos originales, resúmenes de Tesis Doctorales, informaciones sobre Congresos y actividades, etc. dentro de los tres ámbitos de la SIBB:

- Área de cirugía ortopédica y traumatología

- Área de biomecánica deportiva

- Área de biomateriales

Espero estar a la altura de las circunstancias y os animo a que participéis activamente en la revista.

Recibid un cordial saludo,

Diego Velasco Bayón 